\title{
Fabrication, Welding, and Inspection Techniques in Preparation for In-reactor Testing of Accident Tolerant Fuels
}

\section{ASME Pressure Vessels and Piping Conference}

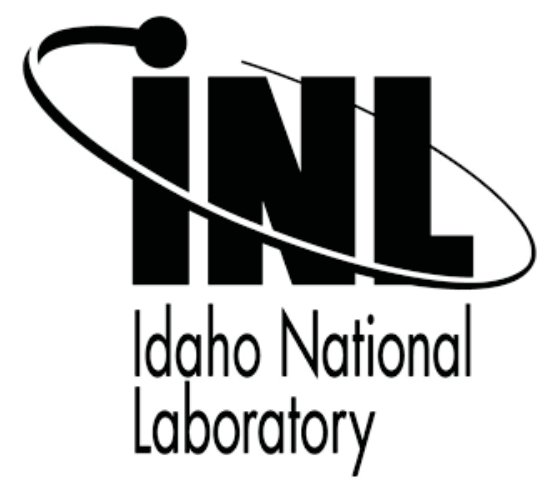

Kristine Barrett, Michael Teague, Glenn Moore, Connor Woolum, Kip Archibald

July 2015

This is a preprint of a paper intended for publication in a journal or proceedings. Since changes may be made before publication, this preprint should not be cited or reproduced without permission of the author. This document was prepared as an account of work sponsored by an agency of the United States Government. Neither the United States Government nor any agency thereof, or any of their employees, makes any warranty, expressed or implied, or assumes any legal liability or responsibility for any third party's use, or the results of such use, of any information, apparatus, product or process disclosed in this report, or represents that its use by such third party would not infringe privately owned rights. The views expressed in this paper are not necessarily those of the United States Government or the sponsoring agency. 



\section{Fabrication, Welding, and Inspection Techniques in Preparation for In-Reactor Testing of Accident Tolerant Fuels}

\author{
Kristine Barrett \\ Idaho National Laboratory \\ Idaho Falls, ID, USA \\ Connor Woolum \\ Idaho National Laboratory \\ Idaho Falls, ID, USA
}

\author{
Michael Teague \\ Idaho National Laboratory \\ Idaho Falls, ID, USA \\ Kip Archibald \\ Idaho National Laboratory \\ Idaho Falls, ID, USA
}

\author{
Glenn Moore \\ Idaho National Laboratory \\ Idaho Falls, ID, USA
}

\begin{abstract}
After the Fukushima events in 2011, DOE-NE in collaboration with nuclear industry shifted R\&D emphasis to accident performance of LWR fuels under extended loss of active cooling and steam exposure. DOE-NE has created a roadmap for the "Development of Light Water Reactor Fuels with Enhanced Accident Tolerance." The mission of the Accident Tolerant Fuel (ATF) Roadmap is to develop the next generation of LWR fuels with improved performance, reliability, and safety characteristics during normal operations and accident conditions and with reduced waste generation. The ultimate goal of the ATF roadmap is to support the insertion of lead fuel rods (LFRs) or lead fuel assemblies (LFAs) of an Accident Tolerant Fuel into a commercial LWR within 10 years (i.e., by the end of FY-2022). As a step toward this goal, an irradiation test series has been developed to assess the performance of proposed ATF concepts under normal LWR operating conditions. Data generated by this test program will be used to establish the feasibility of certain aspects of proposed ATF concepts, as well as provide information to support screening among concepts; as such, it is an integral part of Phase I: Feasibility Assessment and DownSelection outlined in the ATF Roadmap. This irradiation test series is planned to be performed as a series of drop-in capsule tests to be irradiated in the Advanced Test Reactor (ATR) operated by the Idaho National Laboratory (INL), and it has been designated as the ATF-1 test series.
\end{abstract}

Current fission reactors use zirconium-based fuel cladding because of its extremely low macroscopic thermal neutron absorption cross-section, good high temperature strength, and decent corrosion resistance. However, advanced, innovative materials may provide these same benefits while increasing reactor safety margin, core power density, and fuel utilization. These advanced fuel cladding systems will allow revolutionary cladding performance and enhanced fuel mechanical designs, however, challenges exist in design, analysis and fabrication of innovative, never before tested, fuel cladding systems for inreactor testing. This paper highlights the challenges associated with design, fabrication and welding, and inspection of innovative materials and actions taken to address those challenges in preparation for the Phase I ATR irradiation testing. The lessons learned from Phase I of this experiment can be used to guide researchers for design and analysis of future in-reactor testing of advanced fuel cladding systems.

\section{INTRODUCTION}

The goal of the Accident Tolerant Fuel (ATF) program is to develop the next generation of LWR fuels with improved performance, reliability, and safety characteristics during normal operations and accident conditions and with reduced waste generation. As shown in Figure 1, the goal of the DOE ATF development program is to support the insertion of lead fuel rods (LFRs) or lead fuel assemblies (LFAs) in a commercial LWR within 10 years (Figure 1). 


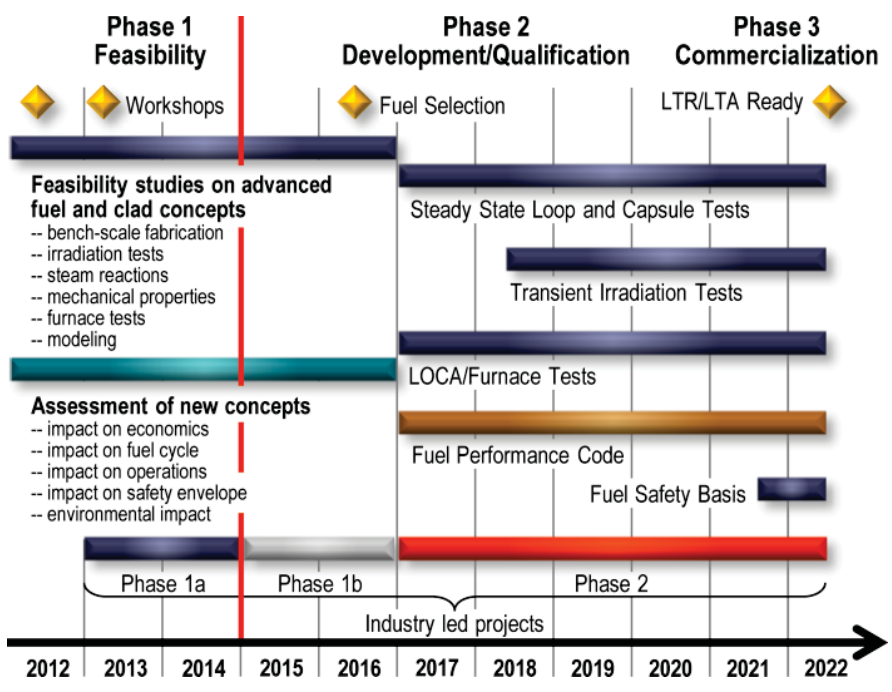

Figure 1. Ten-Year Strategy for Accident Tolerant Fuel Development [2].

As a step toward these test goals, an irradiation test series has been defined to assess the performance of proposed ATF concepts under normal LWR operating conditions. Data generated by this test program will be used to establish the feasibility of certain aspects of proposed ATF concepts, as well as provide information to support screening among concepts; as such, it is an integral part of "Phase I: Feasibility Assessment and Down-Selection" outlined in the ATF Roadmap. This Phase I irradiation test series is planned to be performed as a series of drop-in capsule tests to be irradiated in the Advanced Test Reactor (ATR) operated by the Idaho National Laboratory (INL), and it has been designated as the ATF-1 Test Series [1].

The ultimate goal of the ATF Program is to demonstrate the performance of proposed fuel and/or cladding concepts that could replace the Zircaloy- $\mathrm{UO}_{2}$ system currently used throughout the LWR industry. The ATF-1 irradiation test series is a necessary step toward such a demonstration. Input has been solicited from ATF Development Teams concerning their ATF concept(s), appropriateness and desire to be included in the ATF-1 irradiation test series.

A set of technical evaluation metrics has been established and is included in the "Advanced Fuels Campaign Light Water Reactor Accident Tolerant Fuel Performance Metrics" report [2] to aid in the optimization and down-selection / prioritization of candidate designs. The assessment process is outlined in

Figure 2. The resultant ranked evaluation can then inform concept down-selection, such that the most promising accident tolerant fuel design option(s) can continue to be developed for LFR or LFA insertion into a commercial reactor within the desired timeframe (by 2022).

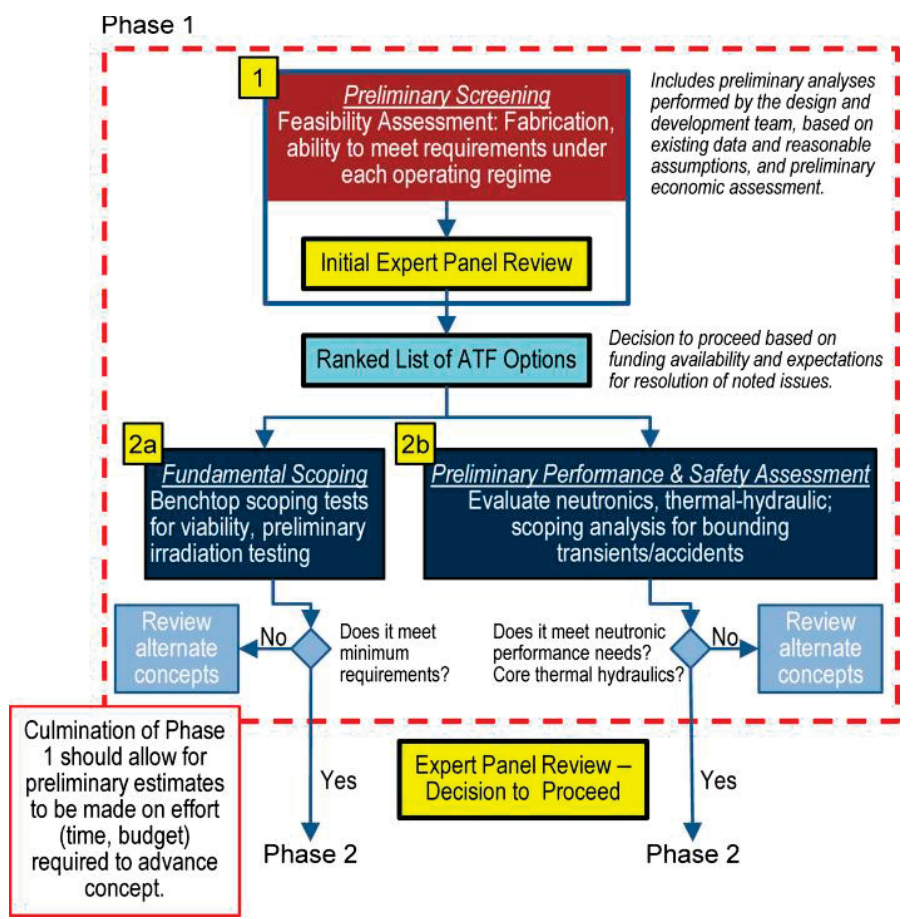

Figure 2. Phase I Feasibility Testing and Concept Selection Process for Phase II Continued Testing [2]

There are many challenges in the design, fabrication, and final assembly of test articles in which innovative materials, never before tested in the ATR, are used for ATR irradiation. These challenges are amplified for "drop-in" experiments where the test rodlet is encapsulated inside a pressure boundary capsule (Figure 3).

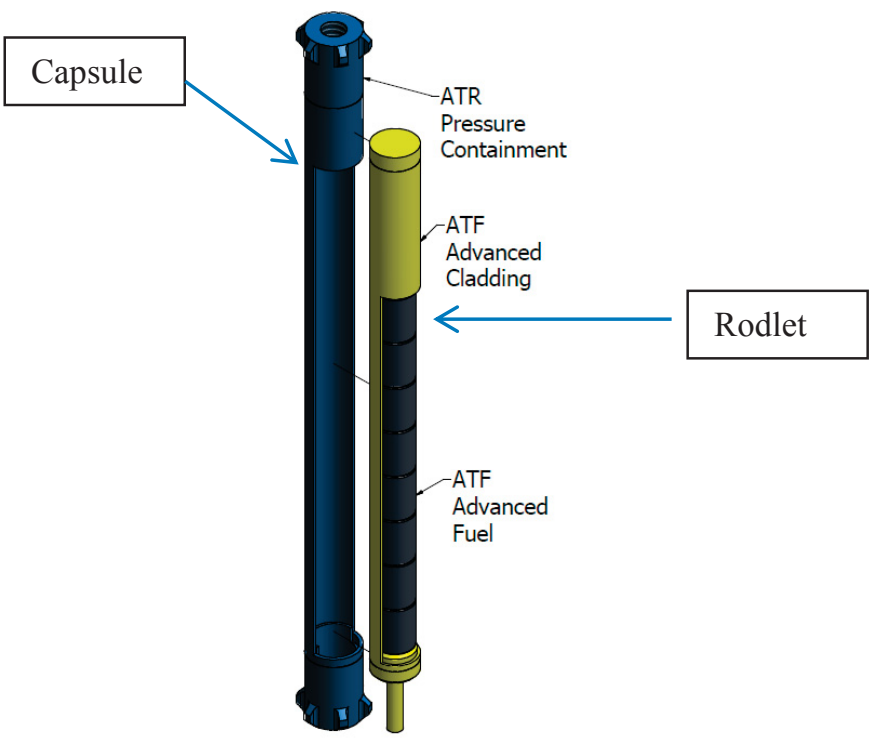

Figure 3. ATF-1 Experiment Assembly [4]. 
The capsule provides two functions. First, it acts as a robust barrier between the primary reactor coolant and the experimental rodlet. Since the rodlet materials are often new and unproven, a potential rodlet breach during irradiation cannot be precluded. Therefore, secondary containment is required to ensure that fuel/fission products cannot be released into the primary reactor coolant. Second, the inert gas-filled gap between the capsule inner wall and rodlet outer wall introduces a thermal resistance that is necessary to elevate the rodlet cladding temperature to a level that is prototypic of LWR cladding. This dual fuel encapsulation introduces design and fabrication challenges in reaching and maintaining the test objective cladding temperature. A design parameter sensitivity analysis performed at INL [3] demonstrated that experiment predicted temperature calculations are most sensitive to the rodlet I.D. and O.D. dimensional uncertainty. The results indicated that a 0.001 inch change in the gas gap between the capsule and the cladding will change the cladding volume weighted average temperature by about $\pm 20 \%$. The maximum and minimum fuel temperatures are also impacted by about $\pm 10 \%$. Therefore, tight tolerances were placed on the rodlet and capsule components to ensure that the nominal designed gas gap would be met during the fabrication process.

The tight component tolerances along with the unknown machining and welding processes for innovative materials introduced challenges in fabricating, machining, welding, and assembling the ATF-1 rodlet and capsules components. This paper describes some of the challenges and lessons learned in designing, machining, welding, and assembling the ATF-1 fuel capsule assemblies and provides a description of the capabilities utilized and/or developed at the INL to address and these challenges.

\section{NOMENCLATURE}

Capsule - A component of the experiment assembly that serves as a primary boundary to isolate the test specimens from the ATR primary coolant system (PCS).

Capsule Assembly - A portion of the experiment assembly that only includes the capsule and internal test specimens.

Cladding - A component of the experiment that encapsulates the specimen and provides a boundary between the specimen and the external environment.

Experiment Assembly - All experiment components configured for placement into the ATRC or ATR core irradiation facility, including the basket.

Fuel Column - One or more fuel slugs/pellets stacked vertically inside a rodlet

Fuel Pellet - Single section of fuel
Irradiation Experiment - An irradiation study of specimens carried out under controlled conditions to answer a scientific question, discover an unknown effect or law, and/or to establish a scientific hypothesis.

Rodlet - A tubular component of the experiment that contains fuel or material specimens and provides an interface with the capsule. A rodlet that contains fuel is typically considered fuel cladding.

Test Specimen - A component of the experiment comprised of fissile and/or other fuels or materials for the purpose of evaluating irradiation behavior and data collection.

\section{METHODOLOGY}

\section{BASIC IRRADIATION TESTING PROCESS FLOW}

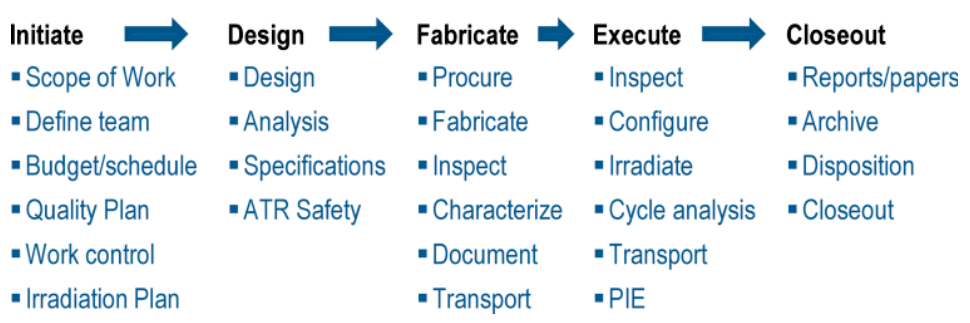

Figure 4. Irradiation Testing Process Flow Chart.

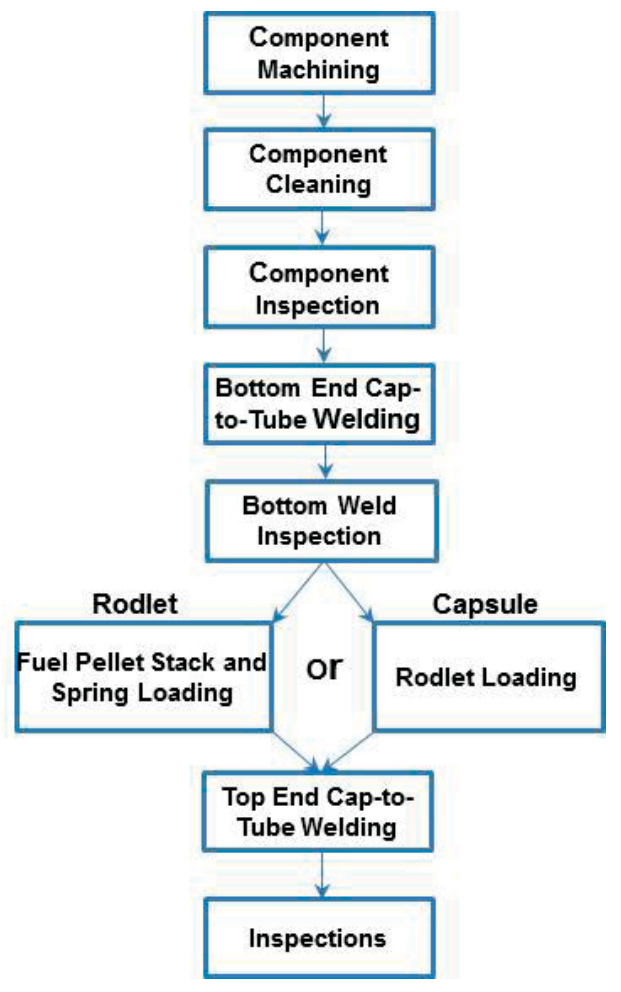

Figure 5. Rodlet and Capsule Fabrication Flow Chart. 
The ATR irradiation testing process is identified in Figure 4. This fabrication process flow chart is identified in Figure 5.

Initiation of the ATF-1 experiment began in 2013 with final design of the safety hardware (i.e., capsule and basket) completion at the end of FY2013. The test specimen (i.e. internal rodlet) design and analysis was completed in midFY2014 and fabrication was initiated shortly thereafter. The first set of ATF-1 fuel capsule assemblies were fabricated and shipped to the Idaho National Laboratory (INL) for insertion in the Advanced Test Reactor (ATR) in February 2015 for cycle 157C1 irradiation testing. Table 1 describes the experiment fuel and cladding types in this initial set of ATF-1 experiments.

Table1. List of ATF-1 Experiment Capsule Assemblies Inserted Cycle 157C in the ATR.

\begin{tabular}{|ccc|}
\hline Capsule ID & Fuel Type & Clad Type \\
\hline ATF-0 & $\mathrm{UO}_{2}$ & $\mathrm{Zr}-4$ \\
\hline ATF-1 & $\mathrm{UO}_{2}$ & $\mathrm{Zr}-4$ \\
\hline ATF-2 & $\mathrm{UO}_{2}$-SiC & $\mathrm{Zr-4}$ \\
\hline ATF-3 & $\mathrm{UO}_{2}$-SiC & $\mathrm{Zr-4}$ \\
\hline ATF-4 & $\mathrm{UO}_{2}$-Dia & $\mathrm{Zr-4}$ \\
\hline ATF-5 & $\mathrm{UO}_{2}$-Dia & $\mathrm{Zr-4}$ \\
\hline ATF-6 & $\mathrm{UO}_{2}$ & Alloy-33 \\
\hline ATF-7 & $\mathrm{UO}_{2}$ & Alloy-33 \\
\hline ATF-8 & $\mathrm{UO}_{2}$ & APMT \\
\hline ATF-9 & $\mathrm{UO}_{2}$ & APMT \\
\hline ATF-10 & $\mathrm{U}_{2} \mathrm{Si}_{3}$ & $\mathrm{Zr-alloy}$ \\
\hline ATF-12 & $\mathrm{U}_{2} \mathrm{Si}_{3}$ & Zr-alloy \\
\hline ATF-13 & $\mathrm{U}_{2} \mathrm{Si}_{3}$ & $\mathrm{Zr-alloy}$ \\
\hline ATF-14 & $\mathrm{U}_{2} \mathrm{Si}_{3}$ & $\mathrm{Zr-alloy}$ \\
\hline ATF-15 & $\mathrm{U}_{2} \mathrm{Si}_{3}$ & $\mathrm{Zr-alloy}$ \\
\hline ATF-18 & $\mathrm{UO}_{2}$ & FeCrAl \\
\hline ATF-20 & $\mathrm{UO}_{2}$ & FeCrAl \\
\hline
\end{tabular}

\section{Design Process}

The ATF-1 irradiation test assembly is based on an existing design that has been used since the late 1990s to test fueled rodlets in the ATR under conditions of temperature and power prototypic of LWRs; this design was originally developed to test mixed-oxide (MOX) fuels for the DOE Fissile Materials Disposition Program [4], and it continues to be referred to as the "MOX hardware" by ATR designers/experimenters. The MOX design was modified to accommodate the ATF-1 experiment requirements and objectives. In particular, the original MOX rodlets did not contain any capsule centering features on the rodlet; small standoffs were added to the rodlet endcaps to center the rodlets in the capsules. Additionally, capsule end caps were modified to press the caps and tubes together to create a backed weld rather than a tube to tube weld. This was necessary to prevent alignment issues with the end caps as observed in previous fabrication efforts.

Scoping thermal analyses were performed to determine the required rodlet-capsule gas gaps to achieve desired fuel and cladding temperatures. Sensitivity of the temperatures to gas gaps was also evaluated and the results affected the tolerances, fabrication and inspection methods utilized [3].

\section{Hardware Fabrication and Inspection Process Development}

The ATF-1 capsules tubes were fabricated using a gun drilling process to meet the tight tolerances required on the inside diameter of the tube. Carbide mandrills were utilized to hold the capsule tubes straight while the outside diameter was turned to final size being sure to hold the wall thickness to the required dimensions. Ultrasonic inspections are performed on parts while still on the lathe to check wall thickness during fabrication. Rodlet tubes were also fabricated using a gun drilling process from Alloy-33 and APMT bar stock provided by the collaborator then machined to size to meet tube outside diameter (O.D.) specifications. The Alloy-33 rodlet tubes were especially difficult to hold dimensional tolerances, therefore a few tubes were fabricated using a plunge wire electrical discharge machining (EDM) - this method showed some improvement at holding the required tolerances.

An inspection process using a coordinate measuring machine (CMM) was developed by the quality inspector to thoroughly characterize the capsule and rodlet tube dimensions. This was particularly beneficial for tubes that had been altered (i.e. machined) from the manufacturer dimensions to meet design specifications. The inspection process was part of a feedback loop with fabrication engineering used to improve fabrication techniques as required to ensure parts met dimensional requirements and fit together properly. Inspections of both diameters (O.D. and I.D.), wall thickness, straightness and coaxial conditions of the diameters were performed to quantify the tubes. Rodlet tubes were inspected with respect to an idealized datum diameter designed to represent a perfect capsule inside diameter. This step was performed to evaluate how the gas gap between the rodlet and a perfect capsule varied in the axial direction. Diameter inspection measurements were taken at axial locations on the rodlet and capsule tubes that align with each other to allow for investigation of gas gaps at those locations.

\section{Welding Process Development}

Development of the rodlet and capsule tube to end-cap welding process began by establishing the process by which welding parameters and qualifications would be performed for each rodlet cladding type and capsule. Initial mock-up weld tests on the benchtop utilized a Gas Tungsten Arc Welding (GTAW) orbital welder; welding was mostly successful with exception of 
weld blow-outs observed on a few tubes, Figure 6. Other weld defects encountered during the weld development and fabrication stage of the effort included, porosity in weld due to less than adequate fit-up of components, e.g. minor chamfer on the inside edge of a cladding tube was sufficient to establish trapped gas during component fit-up resulting in porosity within the weld. A risk evaluation of the weld blow-outs was performed using short assemblies and assemblies loaded with metal fillers to take up the plenum space inside the tube. Once this process was demonstrated successfully, welding of mock-up tubes was performed in an Argon purged negative pressure glovebox to validate the process under prototypic conditions. The welding activities inside the glovebox did not yield "like" results, namely an increased occurrence of weld blow-outs was encountered.

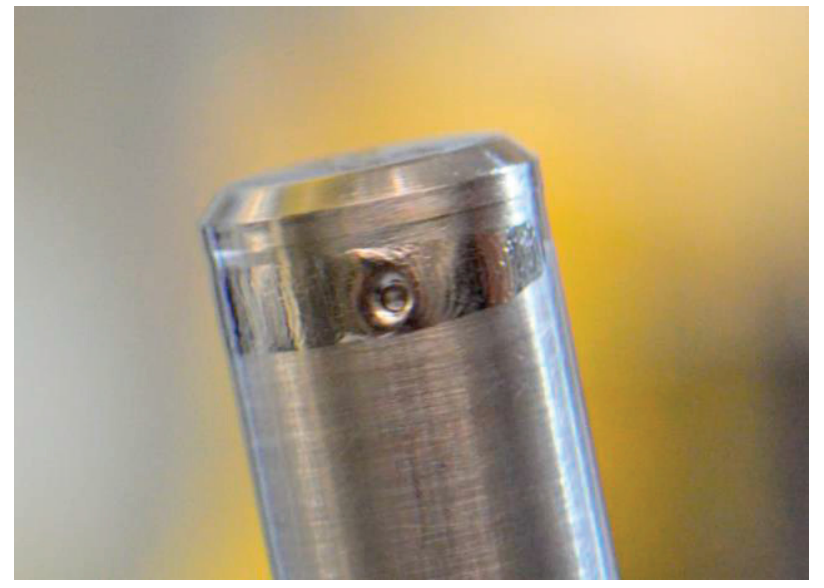

Figure 6. Rodlet top end cap weld showing "blow-out".

Several steps were taken to identify the cause of the blow-outs observed in the glovebox to improve the welding success rate:

- A slight cap side tungsten weld tip alignment was made. Location of the tungsten electrode appeared to be critical. If the electrode was too far to the tube side then local pockets of entrapped gas were observed in the weld region.

- Orbital welding heat input sequences were established to minimize the heat affected zone (HAZ).

- Copper chill blocks, in proximity to the weld region were configured to minimize HAZ and mitigate gas pressure build-up of the plenum gas.

- Heat was found to be a major factor in weld success rate:

- Pre-cooled rodlets and capsules prior to welding.

- Allowed welder and chill blocks to cool back to room temp between welds.

- Machined square edges on the weld components to improve proper fit-up.

- Sharpened inside corners of the mating parts to ensure a tight joint at the weld.

- Improved quality and cleanliness of the weld components to prevent potential for entrapped gas near weld.

- $\quad$ Tapered the end-caps to assist in a press fit assembly.
- Used various jigs to line up components in welding fixtures for consistency.

- Component fit-up tolerance requirements were established.

- Component cleaning requirements were established.

- A bake-out procedure for the U3Si2 fuel was established to remove moisture that may have wicked into the fuel during final sizing/machining.

- Configuration of fixtures, i.e. clamps and stops, facilitating reproducible weld bead placement.

- $\quad$ Mock-up rodlet welding sequences were initially performed using a stainless steel insert. Later, a more appropriate thermal insulator, quartz, was utilized.

\section{RESULTS}

\section{Design}

The irradiation test assembly consists of an aluminum experiment basket, inside of which are $316 \mathrm{~L}$ stainless steel capsule(s) that serve as the primary safety (i.e., pressure) boundary, each of which encapsulates a single test rodlet made of fuel/material test specimens inside cladding (Figure 7). The experiment basket is designed to hold multiple, vertically stacked capsule assemblies (Figure 8). Each capsule assembly is independent, meaning it can be introduced into, or removed from, an experiment basket during any ATR outage.

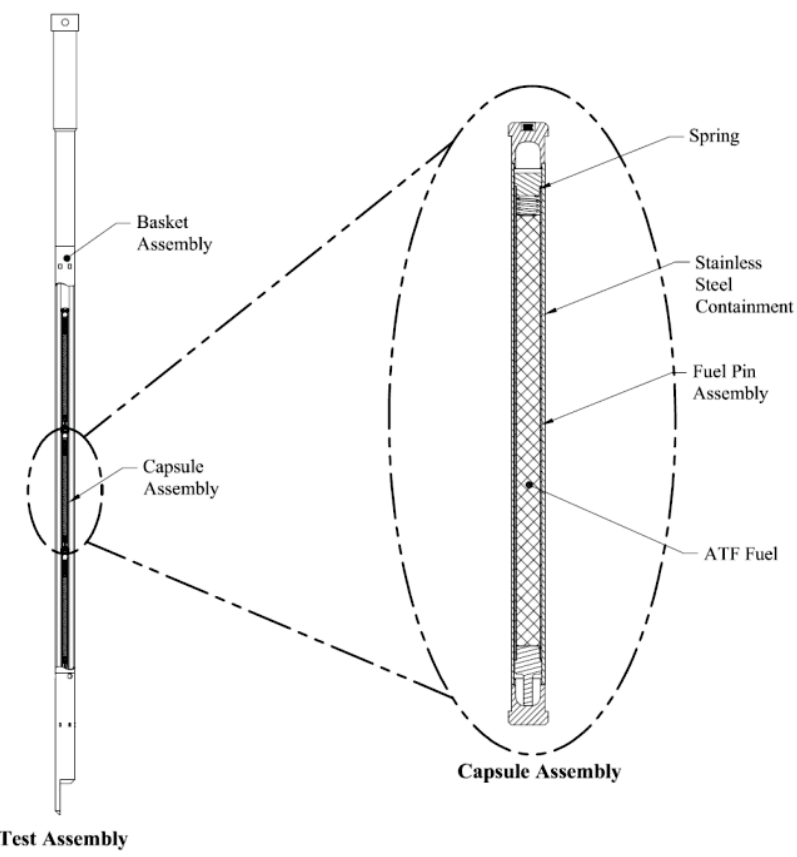

Figure 7. ATF-1 Experiment Assembly [1]. 


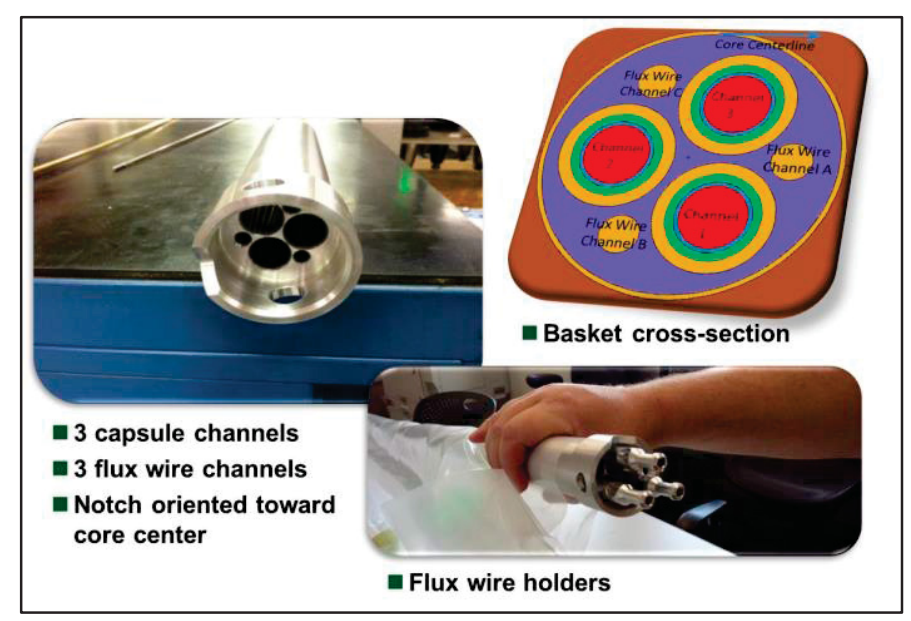

Figure 8. ATF-1 3 Hole Basket. Notch is oriented toward ATR core centerline.

The rodlet assembly is shown in Figure 3. All rodlets utilized a solid end cap design; a 0.125 in. long "cap-in-tube" fit-up, Figure 9.

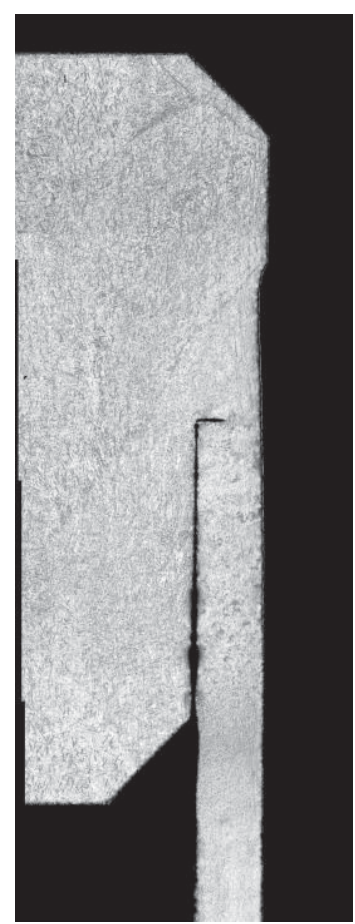

Figure 9. Illustration of rodlet end cap geometry.

The original fit up design of the end-caps shown in Figure 10 posed serious challenges in the welding process. Time did not permit revision of the end-cap design for the original set of ATF1 rodlets in FY-14, however the end-cap design is being revised for assembly of all planned and future rodlet assemblies in FY15 and beyond.

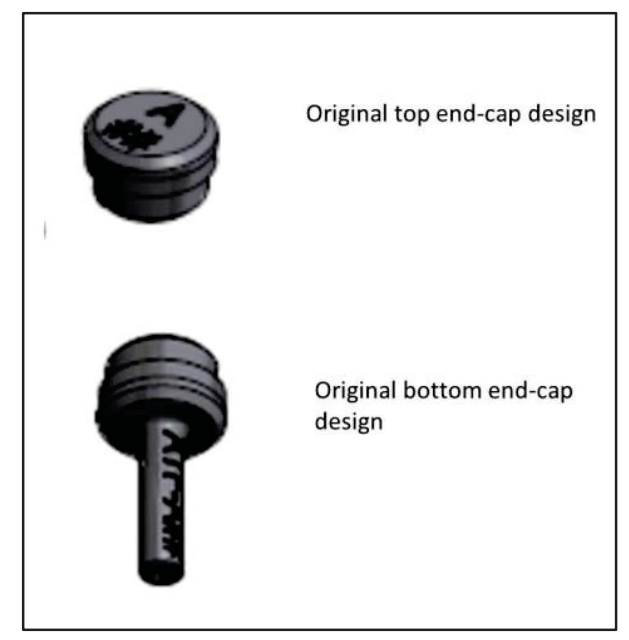

Figure 10. Original ATF-1 rodlet end-cap design.

\section{Machining}

Capsules were fabricated using ASME SA479/316L stainless steel components. For capsule end-caps, a hollow end-cap design was employed. An end cap back-wall thickness of 0.049 in. was established at the tube fit-up joint; a 0.125 in. long "cap-in-tube" fit-up was employed. Capsules were successfully machined meeting the dimensional tolerances required to mate with the rodlets and maintain rodlet-capsule gas gaps in the required ranges. Machining capsule tubes from bar stock involved gun drilling then reaming the stock material. In-process inspection of the components was often performed in order to ensure the tight tolerances were maintained throughout fabrication. A hone is in the process of being procured to further refine the machining process and allow for more precise control of tube inner diameter and straightness.

Rodlet parts (fuel, cladding, and end-cap material) were supplied by the ATF-1 collaborators. For the most part, the tubes were commercial grade Zr-alloy. The APMT, and Alloy-33 rodlet materials were all machined at the INL from bar-stock material provided by the collaborator. Machining of rodlet tubes followed the same general process as capsule tube fabrication. The FeCrAl rodlets were assembled at Oak Ridge National Laboratory (ORNL) in Oak Ridge, TN.

The Alloy-33 parts were very difficult to machine to tolerance and were never fabricated exactly to specification. Alternatively, special inspection techniques and careful hardware selection was used to pair each Alloy-33 tube with a capsule tube to prevent excessively large gas gaps resulting in unacceptably high cladding temperatures.

\section{Welding}

Gas Tungsten Arc Welding (GTAW), also referred to as Tungsten Inert Gas (TIG) welding, was selected as the welding method for both rodlet and capsule fabrication. Model 4-500 Bench-top 
orbital welder manufactured by Arc Machines Inc., (AMI), Pacoima, CA was used in the fabrications effort. The weld head, used to prepare "fueled" rodlets and capsules was configured in a MBraun Labmaster SP glove box purged with helium. The fill gas for the rodlets and capsules was helium; with exception of one rodlet that required higher irradiation fuel temperature. It was backfilled with a fill gas composition of $75 \% \mathrm{Ar}, 25 \% \mathrm{He}$.

Welding was performed using $2 \%$ ceriated tungsten electrodes, 0.040 in. diameter. A nominal arc gap of $0.030 \mathrm{in}$. was used, per the manufacturer's recommendation (Figure 11). During welding, the weld region was purged with flowing helium at a rate of 15 cubic feet per hour $(\mathrm{CFH})$.

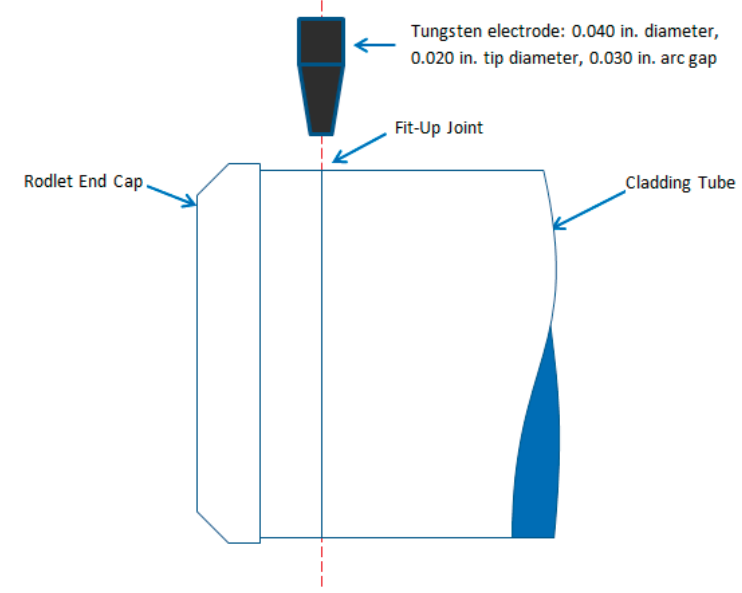

Figure 11. Sketch of orbital welding electrode configuration.

The final fuel rodlet welding process consisted of following steps:

1) An initial fix-position, pulsed current, "drill down" facilitating weld penetration.

2) Pulsed welding around the full circumference of the tube at a continuous speed of $\sim 5-23$ inches per minute (IPM)

a. Rate of arc pulsing, peak current to background current level, was used to facilitate a weld bead $\sim 50 \%$ step-over (bead overlap)

b. Welding power/current was incrementally decreased, in typically two or three steps, as the welding proceeded; in order to compensate for the heat buildup in the components being welded.

3) Following the full perimeter welding sequence, a gradual tail-off of the current "down-slope" was used, with travel, to complete the weld.

Welding success was improved with the design and implementation of an end cap chill block component facilitating precise and reproducible positioning of the welding electrode relative to the target alignment position; approximately 0.005 0.010 in. cap-side of fit-up joint. In this configuration the welding sequence, in most cases, produced acceptable results.
Concurrent with the fueled rodlet fabrication effort, weld performance modeling was performed. Simulation results established that less than full penetration welds were acceptable for the anticipated irradiation experiment conditions. Subsequently, rodlets having less than full penetration welds were qualified for irradiation testing; on a case-by-case basis. Figure 12 shows an image of a successful rodlet top end cap closure weld.

All fabricated "fueled capsules" required full penetration, defect free welds, in order to be meet ASME Section III, Class 1 pressure vessel certification requirements

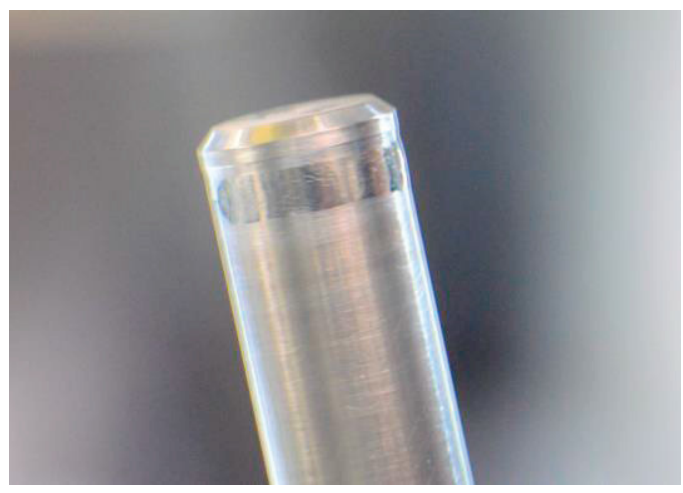

Figure 12. Example of a successful rodlet top end cap weld.

After rodlet welds passed visual inspection in the glovebox, a microfocal X-Ray Imaging System configured with a rotating sample stage and a 1920 x 1536 pixel array; North Star Imaging, Inc. Rodgers, $\mathrm{MN}$, was performed to determine weld $\%$ penetration at the rodlet/end-cap joints (top and bottom). Calculations were performed to determine acceptance criteria for the weld penetration on $\mathrm{Zr}$-alloy and Alloy-33 cladding rodlets [5]. Engineering judgement and collaborator acceptance of the other cladding rodlets (i.e. FeCrAl and APMT) was used for weld acceptance since not enough information on the material mechanical properties of these materials was known to perform the calculations. Once weld penetration acceptance was obtained for the rodlets, they were loaded into the capsules (with the bottom end-cap seal welded at $100 \%$ weld penetration - see Figure 13) then the capsule top end-cap was seal welded in the glovebox for final assembly. 


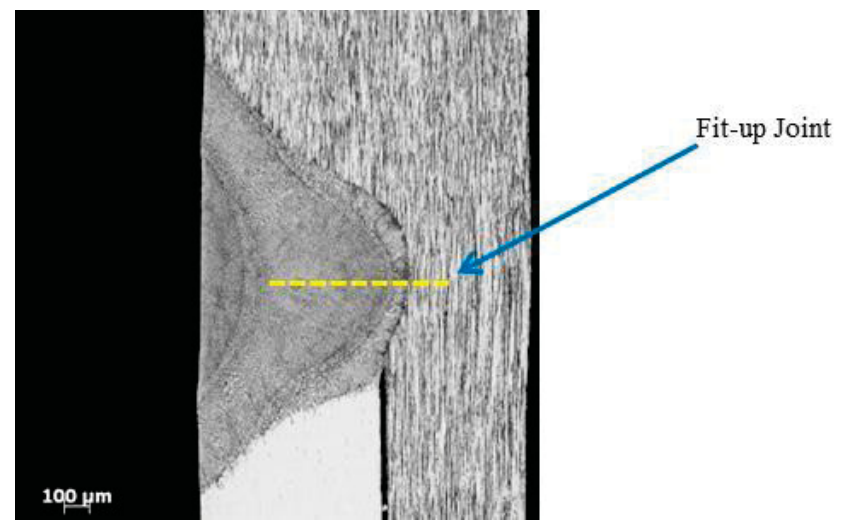

Figure 13. Full perpetration capsule end-cap weld (316L SS)

\section{Final Inspection}

Dimensional inspection of individual fuel pellets was performed to identify fuel/cladding gas gaps used in the "as-built" fuel temperature prediction calculations. CMM dimensional inspection was performed to support matching of the rodlet/capsule end cap pairs to ensure an interference fit between end caps and the tubes. The CMM rodlet/capsule dimensional measurements were also used to match rodlet and capsule pairs to ensure design gas gaps as close to nominal dimensions were met.

Rodlet welds were visually (VT), radiographically (RT) and He leak test (LT) inspected. RT was performed using both computer radiography (CR) and digital radiography (DR) techniques. Capsule components were procured as ASME Section III, Class 1 and received penetrant (PT) examination on all machined surfaces. Capsule welds were VT, PT, LT and RT inspected in accordance with ASME, Section III, Class 1 code requirements.

High resolution radiography was used to identify weld penetration, gas pockets, and other disqualifying features. Metallography was used to determine weld penetration and examine the heat affected zone.

\section{SUMMARY AND CONCLUSIONS}

This paper highlights the challenges associated with design, fabrication, welding, and inspection of innovative materials and actions taken to address those challenges in preparation for the Phase I ATR irradiation testing. Several improvements to conventional fabrication, welding, and inspection processes were necessary to meet dimensional tolerance weld acceptance criteria. The improvements included a higher level of rigor in the component cleaning process, fuel bake-out after machining, redesign of the end-cap fit-up, re-alignment of the tungsten weld tip, orbital weld heat input parameter changes (higher rotation speed, lower power), use of chill blocks to cool components during welding, and use of jigs to maintain position of components during welding. CMM dimensionsal inspections improved capsule/rodlet pairing and high resolution radiography along with metallurgic inspections aided in weld acceptance for the rodlets. The end-cap is being re-designed to further improve the assembly and welding success rate for future ATF fuel rodlet assemblies. The lessons learned from Phase I of this experiment can be used to guide researchers for design and analysis of future in-reactor testing of advanced fuel cladding systems.

\section{ACKNOWLEDGMENTS}

The development of this paper was supported by the U.S. Department of Energy (DOE) Fuel Cycle Research and Development (FCRD) Advanced Fuels Campaign (AFC). This paper has been approved for conference presentation (INL/CON15-34788).

Acknowledgements for support of the ATF experiments at the INL go to the following:

\begin{tabular}{|c|c|}
\hline Jon Carmack & FCRD National Technical Director \\
\hline $\begin{array}{c}\text { Shannon } \\
\text { Bragg-Sitton }\end{array}$ & $\begin{array}{c}\text { FCRD Deputy National Technical } \\
\text { Director }\end{array}$ \\
\hline $\begin{array}{l}\text { Heather } \\
\text { Chichester }\end{array}$ & FCRD Irradiation Testing Technical Lead \\
\hline Steven Hayes & $\begin{array}{l}\text { ATF Fuel Performance Principal } \\
\text { Investigator }\end{array}$ \\
\hline Jason Harp & $\begin{array}{c}\text { ATF Fuel Performance and PIE Principal } \\
\text { Investigator }\end{array}$ \\
\hline Brian Durtschi & Design Engineer \\
\hline James Reseigh & Quality Inspector \\
\hline Misti Lillo & Physics Analyst \\
\hline $\begin{array}{l}\text { Christopher } \\
\text { Glass }\end{array}$ & Physics Analyst \\
\hline Warren Jones & Thermal Analyst \\
\hline Stephen Evans & ATR Representative \\
\hline Michael David & ATR Experiment Engineer \\
\hline $\begin{array}{l}\text { Christine } \\
\text { White }\end{array}$ & Graphic Artist \\
\hline $\begin{array}{c}\text { Steven } \\
\text { Galbratigh }\end{array}$ & FCRD Quality Engineer \\
\hline
\end{tabular}




\section{REFERENCES}

1. Irradiation Testing of Accident Tolerant Fuels in the ATR: The ATF-1 Test Series, PLN-4444, Idaho National Laboratory, April 2013.

2. Advanced Fuels Campaign Light Water Reactor Accident Tolerant Fuel Performance Metrics, INL/EXT-13-29957, U.S. DOE Office of Nuclear Energy, February 2014.

3. J. Ott and R. N. Morris, Irradiation Tests of Mixed-Oxide Fuel Prepared with Weapons-Derived Plutonium, Journal of Nuclear Materials, Vol. 371 (2007) pp.314-328.

4. K. E. Barrett, K. D. Ellis, C. R. Glass, G. A. Roth, M. P. Teague, J. Johns, Critical Processes and Parameters In the Development of Accident Tolerant Fuels Drop-In Capsule Irradiation Tests, Submitted to Nuclear Engineering Design, January 2015.

5. Structural Analysis of Partial Penetration Welds For ATF1 Rodlets. The ATF-1 Test Series, ECAR-2663, Idaho National Laboratory, February 2015. 